\title{
Factor analysis for the adoption of nuclear technology in diagnosis and treatment of chronic diseases
}

\author{
Análise de fatores para adoção da tecnologia nuclear no diagnóstico e \\ tratamento de doenças crônicas
}

\author{
Renato Cesar Sato ${ }^{1}$, Désirée Moraes Zouain²
}

\begin{abstract}
Objective: To identify and evaluate latent variables (variables that are not directly observed) for adopting and using nuclear technologies in diagnosis and treatment of chronic diseases. The measurement and management of these latent factors are important for healthcare due to complexities of the sector. Methods: An exploratory factor analysis study was conducted among 52 physicians practicing in the areas of Cardiology, Neurology and Oncology in the State of Sao Paulo who agreed to participate in the study between 2009 and 2010. Data were collected using an attitude measurement questionnaire, and analyzed according to the principal component method with Varimax rotation. Results: The component matrix after factor rotation showed three elucidative groups arranged according to demand for nuclear technology: clinical factors, structural factors, and technological factors. Clinical factors included questionnaire answers referring to medical history, previous interventions, complexity and chronicity of the disease. Structural factors included patient age, physician's practice area, and payment ability. Technological factors included prospective growth in the use of nuclear technology and availability of services. Conclusions: The clinical factors group dimension identified in the study included patient history, prior interventions, and complexity and chronicity of the disease. This dimension is the main motivator for adopting nuclear technology in diagnosis and treatment of chronic diseases.
\end{abstract}

Keywords: Chronic disease; Diagnostic imaging; Therapeutics; Biomedical technology; Nuclear medicine; Radioisotopes; Health services administration

\section{RESUMO}

Objetivo: Identificar e avaliar as variáveis latentes (que não podem ser observadas diretamente) no processo de adoção e uso de tecnologias nucleares no diagnóstico e tratamento de doenças crônicas. A mensuração e a gestão dos fatores latentes são importantes dentro da área da Saúde devido às complexidades inerentes do setor. Métodos: Foi realizado um estudo do tipo fatorial exploratório com 52 médicos das especialidades de Cardiologia, Neurologia e Oncologia no Estado de São Paulo que participaram do estudo entre 2009 e 2010. Os dados foram coletados por meio de questionário de mensuração de atitudes e analisados pelo método dos componentes principais, com rotacionamento do tipo Varimax. Resultados: A matriz de componentes após a rotação dos fatores apresentou três agrupamentos explicativos ordenados para a demanda de uso das tecnologias nucleares: fatores clínicos, fatores estruturais e fatores tecnológicos. 0 fator clínico é formado por respostas referentes a histórico clínico, intervenção anterior, complexidade e cronicidade. 0 fator estrutural é composto por idade do paciente, área de atuação do médico e capacidade de pagamento; o fator tecnológico diz respeito às perspectivas de aumento do uso da tecnologia nuclear quantidade de serviços. Conclusões: A dimensão de fatores clínicos é composta por histórico clínico, intervenção anterior, complexidade e cronicidade da doença. Essa dimensão é o principal motivador para adoção da tecnologia nuclear no diagnóstico e tratamento das doenças crônicas.

Descritores: Doença crônica; Diagnóstico por imagem; Terapêutica; Tecnologia biomédica; Medicina nuclear; Radioisótopos; Administração de serviços de saúde

\section{INTRODUCTION}

The adoption and diffusion of technology in hospitals and healthcare organizations rely on the knowledge and perception that the agents - physicians, nurses

\footnotetext{
Study carried out at Universidade Federal de São Paulo - UNIFESP, São Paulo (SP), Brazil; and Instituto de Pesquisas Energéticas e Nucleares - IPEN, São Paulo (SP), Brazil.

1 Universidade Federal de São Paulo - UNIFESP, São Paulo (SP), Brazil.

2 Instituto de Pesquisas Energéticas e Nucleares - IPEN, São Paulo, (SP), Brazil.

Corresponding author: Renato Cesar Sato - Rua Talim, 330 - Vila Nair - Zip code: 12231-280 - São José dos Campos (SP), Brazil - Phone: (12) $3921-9598$ - E-mail: rcsato@unifesp.br

Received on on: Sep 29, 2011 - Accepted on: Feb 7, 2012
}

Conflict of interest: None 
and other healthcare professionals - have about this technology. The healthcare sector was extremely benefited from technological advances that helped promote survival of patients and cure of diseases once considered as fatal. The growth in the use of technologies in this area has been of fundamental importance to maintaining this progress; however, the technology adoption process does not occur immediately, nor should it. This process should be guided by a consistent decision-making process, to ensure a sensible use of the institutional resources. This decision-making must also meet the expected success in adopting the technology, i.e., it is too costly a failure when a technology is not perceived as adequate by the agents that potentially will be using it.

In view of these issues, an empirical study was conducted aiming to identify latent variables to complement the decision-making process on technology adoption. In this study, a statistical exploratory factor analysis was used to combine the subjects of chronic diseases and the use of nuclear technology in their diagnosis and treatment. As chronic diseases, we considered those with a low risk of life in the short term, although they may result in severe conditions and require prolonged medical attention ${ }^{(1)}$.

This selection was based on the scenario of a growing importance of chronic diseases in the disease burden of developing countries. In these countries, the increasing prevalence of chronic diseases is a concern for companies, organizations, and individuals. The main reasons for this concern are the high costs generated by these diseases for public health systems and private sectors, as well as the impact on the quality of life of the individuals affected by these conditions. Heart diseases, cancer, and neurological diseases are the main causes of deaths and disabilities in general populations.

A partial explanation for the increase in the chronic disease burden is the advancement in treatment of infectious diseases. In Brazil, these diseases account for $66 \%$ of the disease burden, and the remainder is attributed to communicable diseases (24\%), and accidents $(10 \%)^{(2)}$. Another reason may be the change in the epidemiological profile of the populations of developing countries. This is a consequence of multiple factors, such as increased urbanization, improvement in healthcare measures against infectious diseases, and lifestyle changes, involving nutrition, smoking habit, alcohol consumption, and regular physical activity ${ }^{(3,4)}$. In Brazil, the regions with the highest chronic disease burden are the South and Southeast regions, with 70 and $69 \%$, respectively. The North and Northeast regions also present high DALY (disability-adjusted life years) rates due to infectious diseases.

While selecting technology, we observed that nuclear technology can help alleviate the effects of chronic diseases through non-invasive procedures for diagnosis and staging of diseases such as cancer. Besides, nuclear technology can also be used in patients suffering from certain neurological disorders and heart diseases. According to the study of the Committee on State of the Science of Nuclear Medicine, of $2007^{(5)}$, clinical applications of nuclear medicine include the following: (I) diagnosis of diseases like cancer, neurological disorders (e.g. Alzheimer's and Parkinson's), and cardiovascular diseases in their early stages, allowing early treatment and reducing morbidity and mortality, (II) non-invasive access for therapeutic measures, reducing patient exposure to toxic treatments and allowing early initiation of treatment, (III) treatment for cancer and certain endocrine disorders (thyroid and neuroendocrine tumors).

Advancement in patient health care is complex and slow. The expansion in the development of nuclear medicine techniques has the potential to expedite, simplify and reduce healthcare costs, and may facilitate the implementation of personalized medicine. These factors demonstrate the dynamics of nuclear medicine in the current context. With the introduction and diffusion of hybrid devices, such as PET/CT, there was an increase in the use and accuracy of diagnostic imaging by nuclear medicine. These methods combine metabolic and anatomic information to determine the extent and severity of certain diseases, and more accurately identify relative risks and improve monitoring of the patient. In the context of the study, despite the technological advances related to chronic diseases, developments are also needed to understand the process of internalization of new technologies and the perceived factors for use and dissemination.

\section{OBJECTIVE}

The objective of this study was to identify factors not directly observable, which nonetheless influence the decision-making process on the use of nuclear technologies for diagnosis or treatment of chronic diseases. The study also evaluated which were the group dimensions of the factors that were identified.

\section{METHODS}

The perception of the agents was measured using a five-point Likert attitude scale, ranging from "Strongly Disagree" to "Strongly Agree". The success of this scale 
is the fact that it is sensitive to retrieve Aristotelian concepts of demonstration of quality, because it recognizes the conflict between opposites, the gradient, and the intermediate situation. Another advantage is the proper relation between precision and accuracy of measurements ${ }^{(6)}$.

Data collection was conducted between March and November 2009. Cardiologists, oncologists, and neurologists that directly or indirectly make use of nuclear technology for diagnosis and/or treatment of chronic diseases participated in this data collection. The samples were selected from the group of members of the Brazilian Cardiology Society, Brazilian Society of Oncology and Regional Medical Board of Sao Paulo. The final sample used in the analysis comprised 52 physicians practicing the aforementioned medical specialties in the metropolitan area of the city of Sao Paulo, in the region of $A B C$ Paulista, in municipalities of the Vale do Paraiba region, in municipalities of the region of Campinas, in the municipalities of the region of Ribeirao Preto and in the region of Sorocaba. Exploratory factor analysis and principal components analysis are statistical techniques applied to a single set of variables when the researcher seeks to find out which variables form coherent subsets and are relatively independent of one another. The correlated variables, which are largely independent of other subsets of variables, are combined into factors that form the structures that tend to reflect the underlying processes by the correlations among variables.

\section{RESULTS}

No multicollinearity in factors was observed using the determinant of the correlation matrix (0.19). Therefore, the dimensionality of the correlation matrix of results was reduced, and the variables that were highly correlated with each other were grouped in factors (Table 1).

The factors obtained determined the dimensions: clinical, structural, and technological. The size of the sample that gave rise to factors was adequate $(0.7)$, having been checked by the Kaiser-Meyer-Olkin (KMO) test, and the intercorrelation was assessed by Bartlett's test of sphericity ( $\mathrm{p}<0.001)$. Vectors were selected as important by the Guttman-Kaiser criterion for latent values greater than one.

Therefore, the first component explained $32.154 \%$ of the variance observed. The second component is based on the residual correlation, and is the linear combination of the observed variables which extracts the maximum variance among those uncorrelated with the first component. The other components also extract the maximum variance based on the residual correlations and are orthogonal to the components extracted. Table 2 shows the components of the matrix after the rotation of factors. Loadings with values smaller than $0.4^{(7)}$ were excluded from the analysis and the remaining values were sorted by size.

The clinical factors include answers regarding the medical history, previous interventions, and complexity and chronicity of the disease. The structural factors comprise answers related to the patient's age, the physician's medical specialty, and payment ability. The technological factors include answers referring to the prospects of increased nuclear technology use in diagnosis and treatment, and the number of nuclear medicine services installed in the location of the respondent.

Table 1. Table of eigenvalues and sums

\begin{tabular}{|c|c|c|c|c|c|c|c|c|c|}
\hline \multirow[b]{2}{*}{ Components } & \multicolumn{3}{|c|}{ Initial eigenvalues } & \multicolumn{3}{|c|}{$\begin{array}{l}\text { Extraction sums of } \\
\text { squared loadings }\end{array}$} & \multicolumn{3}{|c|}{$\begin{array}{l}\text { Rotation sums of } \\
\text { squared loadings }\end{array}$} \\
\hline & Total & Variance (\%) & $\begin{array}{c}\text { Cumulative } \\
\text { variance } \\
(\%)\end{array}$ & Total & Variance $(\%)$ & $\begin{array}{c}\text { Cumulative } \\
\text { variance } \\
(\%)\end{array}$ & Total & Variance (\%) & $\begin{array}{c}\text { Cumulative } \\
\text { variance } \\
(\%)\end{array}$ \\
\hline 1 & 3.21 & 32.15 & 32.15 & 3.21 & 32.15 & 32.15 & 3.18 & 31.80 & 31.80 \\
\hline 2 & 1.70 & 17.04 & 49.20 & 1.70 & 17.04 & 49.20 & 1.67 & 16.79 & 48.59 \\
\hline 5 & 0.82 & 8.21 & 81.49 & & & & & & \\
\hline 6 & 0.67 & 6.76 & 88.25 & & & & & & \\
\hline 7 & 0.46 & 4.60 & 92.85 & & & & & & \\
\hline 8 & 0.38 & 3.84 & 96.69 & & & & & & \\
\hline
\end{tabular}


Table 2. Matrix of rotated components

\begin{tabular}{lrrc}
\hline Factor & $\mathbf{1}$ & $\mathbf{2}$ & $\mathbf{3}$ \\
\hline Medical history prior to current illness & 0.92 & & \\
Previous intervention on current disease & 0.89 & & \\
Complexity of current disease & 0.85 & & \\
Chronicity of current disease & 0.79 & & \\
Patient age & & 0.74 & \\
Medical specialty (agent) & 0.72 & \\
Insurance payment and coverage & \multicolumn{2}{c}{0.64} & \\
Growth of nuclear diagnostic procedures & & & 0.74 \\
Growth of nuclear treatment procedures & & & 0.67 \\
Availability of nuclear medicine services & & & 0.59 \\
\hline
\end{tabular}

Table 3 shows the correlation matrix extracted using principal components analysis and rotated using the Varimax method with Kaiser normalization. The table suggests an interdependence of factors.

Table 3. Correlation matrix

\begin{tabular}{lccc}
\hline Component & $\mathbf{1}$ & $\mathbf{2}$ & $\mathbf{3}$ \\
\hline 1 & 0.99 & 0.04 & 0.13 \\
2 & 0.00 & 0.92 & -0.37 \\
3 & -0.14 & 0.37 & 0.91 \\
\hline
\end{tabular}

\section{DISCUSSION}

The technological advancements in equipment, artifacts and other services are designed to mitigate the impact of the disease, even if marginally ${ }^{(5)}$. However, the technologies used in healthcare are not independent of values and perceptions of those involved in the process of technology use. This promotes the emergence of a more complex structure to include, in the process of understanding, elements which cannot be directly observed. The use of exploratory factor analysis identified the grouping of variables revealing associations between them, which in context provides important directions on the predominant perception among agents ${ }^{(6,7)}$. The results obtained by the study allowed to define an explanatory and ordinal construct of factors, which can be divided into three groups.

The first group refers to the clinical condition, including clinical history, the earlier interventions, the complexity of the disease and its chronicity. The second group consists of the patient's age, the area of activity of the agent and the availability of medical payments coverage. The third group of factors concerns the technological conditions, such as the prospects for increased use in diagnosis and treatment, and availability of services. This suggests that demand for the use of nuclear technology in diagnosis and treatment of chronic diseases depends primarily on the patient's clinical condition, followed by structural factors and prospects for development and technological availability. As to the perception of agents, the demand must prioritize the results that might be obtained by the available or potential technology. Similarly, a new technology may also have slower adoption if the agents' perceptions of the clinical aspects cannot be satisfied on a priority basis. Thus, while the expectations of growth in the number of chronic diseases pose a serious problem for the next few years ${ }^{(2,3)}$, especially given the higher probability of hospitalization of patients affected by this type of disease. The factors referred to as "clinical" should be taken into consideration in the adoption process of a technology, so it can offer a return within an efficient frontier. The use of structured information can lead to a more efficient process of technological diffusion and mitigate the risks of spending on economically costly artifacts if they do not meet expectations. In the last century, among the main achievements of medicine were the development of clinical epidemiology and a partial control of infectious diseases. In the first decade of this century, chronic diseases are emerging as a major area of attention. And as in the last century, today's challenges can benefit from the use of technology to bring solutions to new problems.

\section{CONCLUSION}

The study showed an important approach to healthcare management and technology adoption, considering the exploratory factor analysis as an aid in determining the perception of agents. The emergence and change in social conditions of diseases also create new demands, which should be considered together. Therefore, medical technology and the social conditions of the disease should be observed together, since technology itself does not represent a guarantee that it will be a useful tool in diagnosis and treatment. When technologies are acquired without a real assessment of the perception of agents, this may lead to underutilization and therefore to a loss of financial resources to properly deal with the issue, especially considering the problem of agency. The analysis process developed in this study can be applied to other technologies and health conditions that permeate healthcare organizations.

\section{REFERENCES}

1. Kuyken W, Orley J, Power M, Herrman H, Schofield H, Murphy B. The world health organization Quality of Life assessment (WHOOOL): position paper from the world health organization. Soc Sci Med. 1995;41(10):1403-9. 
2. Banco Mundial. Brasil, Enfrentando o desafio das doenças não transmissíveis no Brasil. Washington, DC: 2005

3. Mathers CD, Loncar D. Updated projections of global mortality and burden of disease, 2002-2030: data sources, methods and results. Geneva: WHO; 2005. 4. Handschin C, Spiegelman BM. The role of exercise and PGC1 in inflammation and chronic disease. Nature. 2008;454(7203): 463-9.
5. Institute of Medicine. Advancing nuclear medicine through innovation Washington, DC: National Research Council and Institute of Medicine of the National Academies; 2008.

6. Pereira J. Análise de dados qualitativos: estratégias para as ciências da saúde, humanas e sociais. São Paulo: Edusp; 1999.

7. Stevens J. Applied multivariate statistics for the social sciences. Hillsdale, $\mathrm{NJ}$ : Routledge; 1996. 